\title{
Parallelism between male mating propensity and chromosome arrangement frequency in natural populations of Drosophila ananassae
}

\author{
B. N. Singh and \\ Sujata Chatterjee
}

Genetics Laboratory, Department of Zoology, Banaras Hindu University, Varanasi 221005, India.

Mating ability of different karyotypes due to sub-terminal (alpha or $\operatorname{In}(2 \mathrm{~L}) \mathrm{A}$ ) inversion in $2 \mathrm{~L}$ from two natural populations of Drosophila ananassae was investigated. The results show that the average number of females inseminated by a single male in 12-hour period varies for different karyotypes in males. The analysis of variance indicates that the differences are highly significant for males in both the populations studied. However, the averages for different karyotypes in females show no variation and thus homo- and heterokaryotypic females are equally receptive. The males heterozygous for inversion show greater mating propensity as compared with homokaryotypic males which provides evidence for heterosis associated with AL inversion in $D$. ananassae with respect to male mating activity. Furthermore, the comparison of male mating propensity with chromosome arrangement frequency in both the natural populations suggests that there is a correlation between mating propensity and chromosome arrangement frequency in natural populations of $D$. ananassae.

\section{INTRODUCTION}

It is known that inversion polymorphism in the genus Drosophila is of frequent occurrence and has adaptive function (Da Cunha, 1960; Dobzhansky, 1970; Sperlich, 1973). Although a number of adaptive functions have been found to be associated with inversion polymorphism, the association of mating propensity with inversion karyotypes is an important one. The correlation between sexual activity and chromosomal polymorphism has been found in $D$. persimilis (Spiess and Langer, 1961, 1964a), D. pseudoobscura (Spiess and Langer, 1964b; Kaul and Parsons, 1965; Parsons and Kaul, 1966; Spiess et al., 1966), D. pavani (Brncic and Koref-Santibanez, 1964), D. subobscura (Sperlich, 1966) and D. robusta (Prakash, 1968). Evidence for rare male mating advantage for inversion karyotypes has also been presented (Ehrman et al., 1965; Anderson and Brown, 1984).

Drosophila ananassae is a cosmopolitan and domestic species. It presents a high degree of chromosomal variability (for reference see Singh, 1982). There is quantitative variation in the frequency of different chromosome arrangements and in the level of inversion heterozygosity in
Indian populations of this species (Singh, 1974, $1984 a, b, 1986$ ). The subterminal (alpha or In(2L)A) inversion in the left arm of second chromosome is cosmopolitan in distribution (Singh, 1970). This is a lengthy inversion occupying nearly 70 per cent of $2 \mathrm{~L}$. The inversion heterozygotes often exhibit heterosis (Singh and Ray-Chaudhuri, 1972; Moriwaki and Tobari, 1975; Singh, 1982). However, the degree of heterosis varies in different strains and intra- and interpopulation crosses (Singh, 1972, 1981, 1983a, b, 1985). The results of mating propensity tests on homo- and heterokaryotypes from natural populations revealed that chromosomal polymorphism in $D$. ananassae may have a partial behavioural basis (Singh and Chatterjee, 1986). During the present study, we analysed two new populations of $D$. ananassae with respect to mating propensity of inversion karyotypes and found a correlation between inversion frequency and male mating propensity.

\section{MATERIALS AND METHODS}

During the course of the present investigation two populations were sampled: 
(1) Madurai (Tamil Nadu, South India). Flies were collected in December 1984. The frequencies of different chromosome arrangements have been described separately (Singh, 1986).

(2) Bhagalpur (Bihar). Flies were collected in October 1985. The results of chromosomal arrangements of this population are reported elsewhere (Singh, 1986).

In each of the two populations, two homozygous stocks (one for ST and the other for AL in $2 \mathrm{~L}$ ) were prepared from the progeny of naturally impregnated females. Two stocks, ST/ST and $\mathrm{AL} / \mathrm{AL}$ were established by crossing different lines of each chromosomal type (from the same population) and this was done for randomisation of genetic background. Heterozygous flies were produced by making reciprocal crosses between ST/ST and AL/AL stocks. ST/AL heterozygotes were obtained by crossing ST/ST females and $\mathrm{AL} / \mathrm{AL}$ males and $\mathrm{AL} / \mathrm{ST}$ heterozygotes were produced by crossing $\mathrm{AL} / \mathrm{AL}$ females with $\mathrm{ST} / \mathrm{ST}$ males. Virgin females and males of different karyotypes ST/ST, ST/AL, AL/ST and AL/AL were collected and aged for seven days. The total mating ability of each karyotypic male to inseminate a number of females was measured by confining a single male with six females of uniform karyotype in a food vial for a 12 -hour period at approximately $24^{\circ} \mathrm{C}$ temperature. After exposing the females to the male for 12 hours, they were separated and dissected in normal saline. The reproductive tracts (vagina, spermathecae and ventral receptacles) of females were examined under a microscope for the presence of sperm which indicated that mating had occurred. In total 16 combinations were made and in each combination 30 males were tested in each of the two populations studied.

\section{RESULTS}

For Madurai and Bhagalpur populations, the average number of females inseminated by a single male in a 12-hour period is shown separately. The data on the average number of females inseminated by a single male for homo- and heterokaryotypes from Madurai population are presented in table 1 . The averages for males with different karyotypes vary from $2.45(\mathrm{ST} / \mathrm{ST})$ to $3 \cdot 52(\mathrm{AL} / \mathrm{ST})$. The heterozygous males are superior to the corresponding homozygotes in mating ability. Between the two homozygotes, AL/AL is superior to ST/ST. The average value for female ranges from $3 \cdot 12$ $(\mathrm{AL} / \mathrm{AL})$ to $3 \cdot 25(\mathrm{ST} / \mathrm{AL})$. The analysis of vari-
Table 1 Average number of females inseminated by a single male in a 12-hour period (Madurai population)

\begin{tabular}{|c|c|c|c|c|c|}
\hline$q$ & $\begin{array}{l}\delta \\
\mathrm{ST} / \mathrm{ST}\end{array}$ & $\begin{array}{l}\delta \\
\mathrm{S}_{L}^{r} / \mathrm{AL}\end{array}$ & $\begin{array}{l}\delta \\
\mathrm{AL} / \mathrm{ST}\end{array}$ & $\begin{array}{l}\delta \\
\mathrm{AL} / \mathrm{AL}\end{array}$ & $\begin{array}{l}\text { Average } \\
\text { for } \\
\text { females }\end{array}$ \\
\hline $\mathrm{ST} / \mathrm{ST}$ & $2 \cdot 63$ & $3 \cdot 60$ & $3 \cdot 46$ & $3 \cdot 17$ & $3 \cdot 21$ \\
\hline ST/AL & $2 \cdot 57$ & $3 \cdot 40$ & $3 \cdot 57$ & $3 \cdot 46$ & $3 \cdot 25$ \\
\hline $\mathrm{AL} / \mathrm{ST}$ & $2 \cdot 43$ & $3 \cdot 43$ & $3 \cdot 43$ & $3 \cdot 17$ & $3 \cdot 12$ \\
\hline $\mathrm{AL} / \mathrm{AL}$ & $2 \cdot 17$ & $3 \cdot 30$ & $3 \cdot 60$ & $3 \cdot 40$ & $3 \cdot 12$ \\
\hline $\begin{array}{l}\text { Average } \\
\text { for males }\end{array}$ & $2 \cdot 45$ & $3 \cdot 43$ & $3 \cdot 52$ & $3 \cdot 30$ & \\
\hline
\end{tabular}

For males: $F=45.857, P<0.0005$

For females: $F=0.761 . P>0.50$

ance is given in table 2 which demonstrates that the difference is highly significant for male karyotypes $(F=45.857, P<0.0005)$. On the other hand, the differences for female karyotypes are not significant $(F=0.761, P>0.50)$. Thus, the results from Madurai population clearly indicate that males with different karyotypes differ greatly in their mating propensity but different karyotypic females are equally receptive. In the Madurai population the chromosomes with $\mathrm{AL}$ gene sequence are more frequent than those with ST sequence. Interestingly, $\mathrm{AL} / \mathrm{AL}$ homozygous males are superior than ST/ST males in mating propensity.

The results of mating ability tests on different karyotypes from Bhagalpur population are presented in table 3. Similar to the Madurai population, there is greater variation in mating ability of males with different karyotypes as compared with females. It is evident from the results that the heterokaryotypic males mate more frequently as compared with the corresponding homokaryotypes and between the two homokaryotypes, $\mathrm{AL} / \mathrm{AL}$ has greater mating propensity than ST/ST. The averages for different karyotypic males range from $2.65(\mathrm{ST} / \mathrm{ST})$ to $4.02(\mathrm{ST} / \mathrm{AL})$. On the other hand, the averages for females with different karyotypes vary from $3 \cdot 44$ to $3 \cdot 58$. The analysis of variance given in table 4 shows that the difference

Table 2 Analysis of variance

\begin{tabular}{lrll}
\hline Source of variation & df & $\begin{array}{l}\text { Sum of } \\
\text { squares }\end{array}$ & $\begin{array}{l}\text { Mean } \\
\text { square }\end{array}$ \\
\hline Male karyotypes & 3 & 2.89 & 0.963 \\
Female karyotypes & 3 & 0.05 & 0.016 \\
Error & 9 & 0.19 & 0.021 \\
Total & 15 & $3 \cdot 13$ & \\
\hline
\end{tabular}

For males: $F=45.857, P<0.0005$

For females: $F=0.761 . P>0.50$ 
Table 3 Average number of females inseminated by a single male in a 12 -hour period (Bhagalpur population)

\begin{tabular}{llllll}
\hline & & & & & \\
& $\delta$ & $\delta$ & $\delta$ & $\begin{array}{l}\text { Average } \\
\text { for } \\
\text { females }\end{array}$ \\
\hline $\mathrm{ST} / \mathrm{ST}$ & 2.83 & 3.93 & 3.90 & 3.60 & 3.56 \\
$\mathrm{ST} / \mathrm{AL}$ & 2.63 & 4.25 & 3.66 & 3.67 & 3.55 \\
$\mathrm{AL} / \mathrm{ST}$ & 2.53 & 4.13 & 4.00 & 3.67 & 3.58 \\
$\mathrm{AL} / \mathrm{AL}$ & 2.63 & 3.77 & 3.75 & 3.63 & 3.44 \\
$\begin{array}{l}\text { Average } \\
\text { for males }\end{array}$ & 2.65 & 4.02 & 3.83 & 3.64 & \\
\hline
\end{tabular}

For males: $F=70.285, P<0.0005$

For females: $F=0.761, P>0.50$

Table 4 Analysis of variance

\begin{tabular}{lrll}
\hline Source of variation & df & $\begin{array}{l}\text { Sum of } \\
\text { squares }\end{array}$ & $\begin{array}{l}\text { Mean } \\
\text { square }\end{array}$ \\
\cline { 1 - 1 } Male karyotypes & 3 & 4.43 & 1.476 \\
Female karyotypes & 3 & 0.05 & 0.016 \\
Error & 9 & 0.19 & 0.021 \\
Total & 15 & 4.67 & \\
\hline
\end{tabular}

For males: $F=70.285, P<0.0005$

For females: $F=0.761, P>0.50$

is highly significant for males $F=70.285, P<$ $0.0005)$ but not significant for females $(F=0.761$, $P>0.50$ ). In the Bhagalpur population, the frequency of $\mathrm{AL}$ chromosome is higher than that of ST chromosome. Between the two homokaryotypes, the mating ability of $\mathrm{AL} / \mathrm{AL}$ males is greater than that of ST/ST males. Thus, the chromosome occurring in high frequency is associated with higher sexual activity of males in both the populations of $D$. ananassae studied. To test the difference in the average numbers of females inseminated between two karyotypic males, a $t$ test was performed. In both the populations, the difference between ST/AL and AL/ST males is not significant (Maduari: $t=1 \cdot 20, P>$ 0.05 ; Bhagalpur: $t=1.46, P>0.05$ ). However, both ST/AL and AL/ST males have significantly greater mating propensity than $\mathrm{AL} / \mathrm{AL}$ males in Bhagalpur population (ST/AL vs. AL/AL: $t=$ $3.55, P<0.05 ; \mathrm{AL} / \mathrm{ST}$ vs. AL/AL: $t=2.455, P<$ $0 \cdot 05$ ). In Madurai population only $\mathrm{AL} / \mathrm{ST}$ males are superior to $\mathrm{AL} / \mathrm{AL}$ males $(t=2 \cdot 5, P<0.05)$.

\section{DISCUSSION}

The results of the present investigation clearly demonstrate that the males with different karyotypes caused due to subterminal (alpha) inversion in $2 \mathrm{~L}$ derived from two separate natural populations of $D$. ananassae show significant variation in mating ability. The inversion heterozygotes exhibit heterosis in both the populations and between the two homokaryotypes, $\mathrm{AL} / \mathrm{AL}$ males have higher mating propensity as compared with $\mathrm{ST} / \mathrm{ST}$ males. Interestingly, the AL chromosomes occur in higher frequency than ST chromosomes in both the populations studied (Singh, 1986). The present results provide evidence that male mating propensity is an important component of fitness. Thus it is important for the maintenance of inversion polymorphism in natural populations of $D$. ananassae. Furthermore, the females with different karyotypes show no variation with respect to sexual activity in both the populations. This striking sex difference in $D$. ananassae supports the suggestion of Spiess (1970) that the set of polygenes necessary for efficient mating in one sex is different from the set in the opposite sex. Furthermore, the males are more subject to intra-sexual selection than females.

The results obtained from different species of Drosophila show that the inversion karyotypes are associated with mating propensity (Spiess, 1970; Parsons, 1973). Spiess and Langer (1961) found consistent association between mating activity and the chromosome arrangement frequencies in $D$. persimilis. The WT/WT homozygotes are superior in mating activity to $\mathrm{KL} / \mathrm{KL}$ homozygotes which accounts for the superiority of WT arrangement in natural and laboratory populations. The WT arrangement is associated with higher mating activity but the females are the principal determiners of mating speed in $D$. persimilis in which there is no evidence of heterosis (Spiess and Langer, 1964a). In D. pseudoobscura, the variation for mating propensity is considerably more for male karyotypes than female karyotypes (Spiess et al., 1966) and the male is the principal determiner of mating success (Spiess, 1970; Parsons, 1973). Heterosis is associated with male sexual activity but occurs in few combinations of gene arrangements (Spiess et al., 1966). The observed frequencies of different gene arrangements in natural populations parallel their mating frequencies (homozygotes only) in D. pseudoobscura (Spiess and Langer, 1964b). Male mating success is a major component of fitness for $D$. pseudoobscura karyotypes in experimental as well as natural populations (Anderson and Watanabe, 1974; Anderson, et al., 1979; Anderson and Brown, 1984). The males heterozygous for inversions have higher sexual activity in $D$. pavani (Brncic and KorefSantibanez, 1964). Sperlich (1966) found greater 
success in mating for males from the populations showing higher polymorphism than those from the populations with low polymorphism in $D$. subobscura. Prakash (1968) presented evidence for chromosomal interaction affecting mating speed in $D$. robusta.

The present results combined with those reported previously (Singh and Chatterjee, 1986) indicate that inversion heterozygotes exhibit heterosis with respect to male mating propensity and the mating propensity parallels chromosome arrangement frequency in natural populations of $D$. ananassae. Furthermore, in D. ananassae, the males are the principal determiners of efficient mating and in this respect it resembles $D$. pseudoobscura and $D$. pavani while it differs from $D$. persimilis.

Acknowledgement The financial support from the CSIR, New Delhi, in the form of Senior Research Fellowship to S.C. is thankfully acknowledged.

\section{REFERENCES}

ANDERSON, W. W. AND BROWN, C. J. 1984. A test for rare male mating advantage with Drosophila pseudoobscura karyotypes. Genetics, 107, 557-589.

ANDERSON, W. W., LEVINE, L., OlVERA, O., POWELl, J. R., DE LA ROSA, M. E., SALCEDA, V. M., CASO, M. I. AND GUZMAN, J. 1979. Evidence for selection by male mating success in natural populations of Drosophila pseudoobscura. Proc. Natl. Acad. Sci., 76, 1519-1523.

ANDERSON, W. W. AND WATANABE, T. K. 1974. Selection by fertility in Drosophila pseudoobscura. Genetics, 77, 559-564.

BRNCIC, D. AND KOREF-SANTIBANEZ, S. 1964. Mating activity of homo- and heterokaryotypes in Drosophila pavani. Genetics, 49, 585-591.

DA CUNHA, A. B. 1960. Chromosomal variations and adaptation in insects. Ann. Rev. Entomol., 5, 95-110.

DOBZHANSKY, TH. 1970. Genetics of the Evolutionary process. Columbia Univ. Press, New York.

EHRMAN, L., SPASSKY, B., PAVLOVSKY, O. AND DOBZHANSKY, TH. 1965. Sexual selection, geotaxis, and chromosomal polymorphism in experimental populations of Drosophila pseudoobscura. Evolution, 19, 337-346.

KAUL, D. AND PARSONS, P. A. 1965. The genotypic control of mating apeed and duration of copulation in Drosophila pseudoobscura. Heredity, 20, 381-392.

MORIWAKI, D. AND TOBARI, Y. N. 1975. Drosophila ananassae. King, R. C. (ed.), In Handbook of Genetics, Vol. 3, Plenum Publishing Corporation, New York, pp. 513-535.

PARSONS, P. A. 1973. Behavioural and ecological genetics: A study in Drosophila. Clarendon Press, Oxford.
PARSONS, P. A. AND KAUL, D. 1966. Mating speed and duration of copulation in Drosophila pseudoobscura. Heredity, 21, 219-225.

PRAKASH, S. 1968. Chromosome interactions affecting mating speed in Drosophila robusta. Genetics, 60, 589-600.

SINGH, B. N. 1970. Distribution of most common inversions of Drosophila ananassae in different parts of India including Andaman and Nicobar Islands. Ind. Biol, 2, 78-81.

SINGH, B. N. 1972. The lack of evidence for coadaptation in geographic populations of Drosophila ananassae. Genetica, $43,582-588$.

SINGH, B. N. 1974. Quantitative variation of chromosomal polymorphism in natural populations of Drosophila ananassae. Cytologia, 39, 309-314.

SINGH, B. N. 1981. Interracial hybridization in Drosophila ananassae. Genetica, 57, 139-142.

SINGH, B. N. 1982. Persistence of chromosomal polymorphism in various strains of Drosophila ananassae. Genetica, 59, 151-156.

SINGH, B. N. $1983 a$. An inversion within the subterminal inversion in Drosophila ananassae. Experimentia, 39, 99-100.

SINGH, B. N. 1983b. Cosmopolitan inversions in Drosophila ananassae. Caryologia, 36, 333-343.

SINGH, B. N. 1984a. Genetic differentiation in natural populations of Drosophila ananassae. Genetica, 63, 49-52.

SINGH, B. N. 1984b. High frequency of cosmopolitan inversions in natural populations of Drosophila ananassae from Kerala, South India. J. Heredity, 75, 504-505.

SINGH, B. N. 1985. Heterosis without selectional coadaptation in Drosophila ananassae. Theor. Appl. Genet., 69, 437-441.

SINGH, B. N. 1986. Genetic differentiation at the level of chromosomal polymorphism in Indian populations of Drosophila ananassae. Unpublished.

SINGH, B. N. AND CHATTERJEE, S. 1986. Mating ability of homo- and heterokaryotypes of Drosophila ananassae from natural populations. Heredity, 57, 75-78.

SINGH, B. N. AND RAY-CHAUDHURI, S. P. 1972. Balanced chromosomal polymorphism in experimental populations of Drosophila ananassae. Ind. J. Exp. Biol., 10, 301-303.

SPERLICH, D. 1966. Unterschiedliche Paarungsaktivitat innerhalb und zwischen verschiedensen geographischen stammen von Drosophila subobscura. Z. Verebungsl., 98, 10-15.

SPERLICH, D. 1973. Populationsgenetik. G. Fisher, Stuttgart.

SPIESS, E. B. 1970. Mating propensity and its genetic basis in Drosophila. Hecht, M. K. and Steere, W. C. (eds.), In Essays in Evolution and Genetics in Honour of Theodosius Dobzhansky. Appleton-Century-Crofts, New York, pp. 315-379.

SPIESS, E. B. AND LANGER, B. 1961. Chromosomal adaptive polymorphism in Drosophila persimilis. III Mating propensity of homokaryotypes. Evolution, 15, 535-544.

SPIESS, E. B. AND LANGER, B. 1964a. Mating speed control by gene arrangement carriers in Drosophila persimilis. Evolution, 18, 430-444.

SPIESS, E. B. AND LANGER, B. 1964b. Mating speed control by gene arrangements in Drosophila pseudoobscura homokaryotypes. Proc. Natl. Acad. Sci., 51, 1015-1019.

SPIESS, E. B., LANGER, B. AND SPIESS, L. D. 1966. Mating control by gene arrangements in Drosophila pseudoobscura. Genetics, 54, 1139-1149. 